\title{
Determination of the duration of dying and death rate due to morphological signs
}

\section{Introduction}

Establishing life expectancy in humans with various types of violent and non-violent death renders substantial assistance to the judicial and investigative organs in establishing the truth during the investigation of crimes. The definition of dying duration of a human as a unified system of a body, as well as the related establishment of death rate according to the morphological characteristics, is one of the oldest and most complex problem of forensic medical thanatology, which still has not received a satisfactory solution. The death rate depends on a number of subjective and objective reasons, which can increase or decrease its rate, and thereby it is influenced not by the duration of the agonal period only, but by tanatogenesis in general. The understanding of the processes which are happening in a dying body involves the measures to resuscitate the person, their timeliness, intensity, and focus. First of all, it is important for the process intime objectification of dying, which will allow to assess the timeliness and completeness of treatment adequately. Therefore, the study of the duration of dying (agonal period) and the death rate based on the morphological characteristics during tanatogenesis analysis at various causes of violent and non-violent death taking into account the influence of external and internal factors will contribute to further development of forensic medical thanatology and the improvement of preventive and supporttive care. Currently, in forensic medicine) death is divided into fast (acute), coming immediately, suddenly, without agonal period, and slow (agonal), advancing slowly and accompanied by agony, lasting several minutes or hours depending on the rate of death onset rate of dying. Originally, this classification based on clinical and instrumental signs, was developed by physiologists and clinicians in the second half of the previous century. Death happening within 12 hours, from whatever causes it may happen, gives the same morphological pattern. This was indicated in scientific works of such famous scientists as D. Sci, Professor, corresponding member AMN the USSR, Avdeev M. I. 1957, Ph. D., Professor, academician of AMS USSR Davydovskiy, I. V., 1966, Ph. D., Professor Kasyanov M. I. 1954. In their works they noted that fluid blood without clots is detected in heart chambers and major blood vessels in case of rapid death. The presence of red blood clots also indicates a short agonal period. In case of prolonged agony a yellowish-white or white convolution is formed by enhancing blood clotting. The following microscopic signs of rapid death were described: acute plethora of capillaries and venous vessels, stasis, small perivascular hemorrhages, and perivascular edema. Despite of the fact that the macro - and microscopic morphological picture of acute death is well known due to scientific works of the previous generation and does not cause any difficulties with its diagnosis, today it is not sufficient for the judgments about the duration and pace of dying.

The determination of the duration and rate of dying is an important part of analysis of tanatogenesis in lethal cases made out at clinicalanatomical conferences in differential diagnosis, such as acute massive blood loss with acute anaemia, sudden death, etc. The duration of the interval between a heart attack and the moment of death allows to
Volume 6 Issue 3 - 2018

\author{
VA Putincev,' DV Bogomolov,' AM Golubev, ${ }^{2}$ \\ DV Sundukov ${ }^{3}$ \\ 'Federal state budgetary institution, Russian Centre of Forensic \\ Medical Expertise, Russia \\ ${ }^{2}$ V.A. Negovsky Research Institute of General Reanimatology, \\ Russia \\ ${ }^{3}$ Peoples Friendship University of Russia, Russia
}

Correspondence: DV Bogomolov, Federal state budgetary institution, Russian Centre of Forensic Medical Expertise, Director - d.m.n.A.V. Kovalev, Russian Ministri of Health, Moscow, 125284, Russia, Email usicc@yandex.ru

Received: June 08, 2018 | Published: June 13, 2018

divide the group of patients died of cardiac diseases into groups of rapid death (within 60 minutes) and of cardiac death with ontinuous duration of disease manifestation up to 1 day (Figure 1). And the formula of the specialty - forensic medicine (specialty: 14.03.05) includes the priority areas of study specified-the study of the causes and thanatogenesis of sudden death, improved methods of diagnosis and prevention. It objectively shows the importance of such studies devoted to morphological changes of dying process in different types of violent and non-violent death for the improvement of methods of diagnostics of the rate of occurrence of death in forensic practice, as well as in solving health problems. In this connection the authors of the FSBI "RCSME" the Ministry of health for several years have been developed the problem of establishing the death rate and the duration of dying based on morphological data.

\section{The aim of the study}

A detailed study of the dynamics of morphological changes of major homeostatic systems of the human body, characterizing the duration of the process of dying in various categories and types of death with the purpose of scientific study and development of available morphological criteria for determining the duration of dying and the rate of occurrence of death.

\section{Material and methods}

The main material of the study included 206 reported cases of death with known process of dying - 14\% (206/1500), which was a selection criterion. This included 110 cases ( 79 of forensic examination of the corpse and 17 in the framework of regular autopsy). The sample material was divided into groups due to the duration of dying (agonal period) as follows:
a. Agonal period of $\leq 15$ to 30 minutes;
b. Agonal period of $>30$ minutes $\leq 2$ hours;
c. Agonal period of $>2 \leq 6$ hours;
d. Agonal period of $>6$ hours $\leq 12$ hours;
e. Agonal period of $>12$ hours. 
The number of cases ranged from 30 to 57 cases in 5 groups. 53 , $30,32,34,57$ cases were selected for the first, for the second, for the third, for fourth and for the fifth group, respectively (see the diagram). In the study the following source of material and the following research methods were used: analysis of information about the death circumstances (cases), a retrospective clinical-anatomical analysis, the main (classical) method of authopsy and histological examination. Additionally orphometric, macroscopic and photographic techniques were used. In one of the cases of fulminant sepsis the method of molecular-biological studies of autopsy material using the PCR method (polymerase chain reaction) was applied for the first time.

Recently, the use of techniques of molecular biology in particular, IHC has increased in the practice of pathology and forensic medicine find study. Our data on the expression of fibrinogen in lung enables to speak about the contribution of the method of IHC-studies into the establishing of the rate and the duration of dying. IHC study method was used in order to identify morphological characteristics in our research. For the accuracy and reliability of the study results, we used morphological and statistical analysis, which included both statistical analysis of morphological characteristics and thanatogenegenic analysis of the cases of selected material of the study. Thanatogenic (semi-quantitative) analysis allowed us to judge about the immediate cause of death and the rate of dying, and to formulate a clinical and anatomical epicrisis as a prerequisite for morphological and statistical analysis (Table 1). The average scores, the errors, average standard deviations, confidence intervals, correlation were calculated and data analysis of morphological characters was performed. The assessment of reliability was conducted using Student's t-test. Differences were considered to be significant at $95 \%$ and more $(p<0.05-0,01)$. Data processing was performed using the licensed version of the software package SAS (Statistical Analysis System) and "Microsoft Excel", which significantly increased the probability of obtaining correct results for the accuracy and reliability of morphological diagnostics of the process of dying.

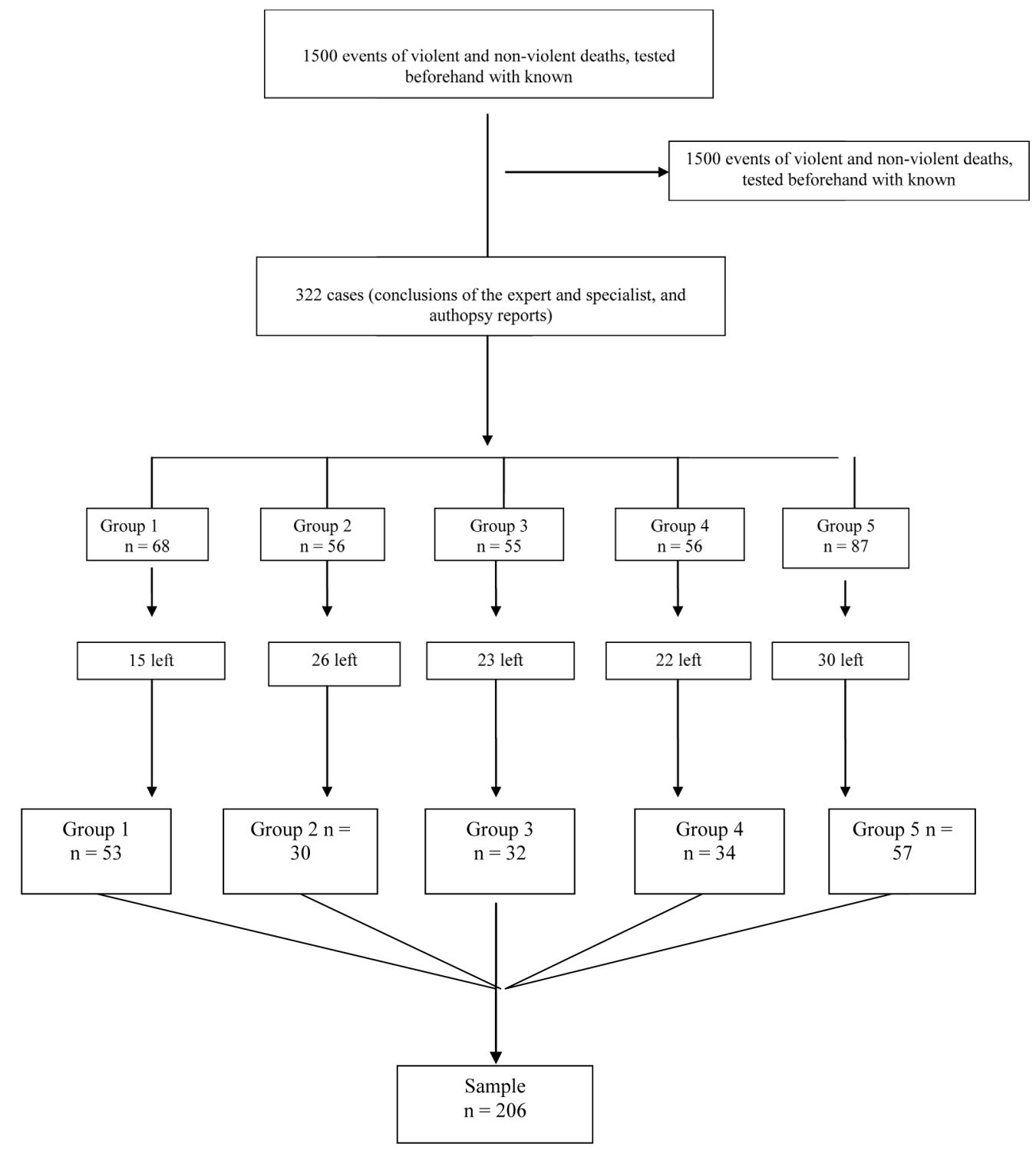

Figure I Scheme of the sampling of the material and its grouping due to time interval. 
Table I Sharing the lethal events with beforehand known process умирания (due to direct reason of the deaths and duration of dying)

\begin{tabular}{|c|c|c|c|c|c|}
\hline \multirow[b]{2}{*}{ Causes of death } & \multicolumn{4}{|c|}{ Time (minutes, hours) } & Total \\
\hline & $\begin{array}{l}\text { I5-30 } \\
\text { minutes }\end{array}$ & $\begin{array}{l}\text { from } 0,5 \\
\text { before } 2 \\
\text { hours }\end{array}$ & $\begin{array}{l}\text { from } 2 \\
\text { before } \\
6 \\
\text { hours }\end{array}$ & $\begin{array}{l}\text { from } 6 \\
\text { before } \\
12 \\
\text { hours }\end{array}$ & $\begin{array}{l}\text { from } 12 \text { hours and } \\
\text { more }\end{array}$ \\
\hline $\begin{array}{l}\text { Death from injury (extensive and / or gross destruction } \\
\text { of the body and its individual parts) }\end{array}$ & 16 & 5 & 2 & 1 & 26 \\
\hline $\begin{array}{l}\text { Complications of trauma, which directly led to death: of } \\
\text { acute massive blood loss }\end{array}$ & 10 & 9 & 10 & 9 & 44 \\
\hline Of shock & 6 & 5 & 3 & 2 & 18 \\
\hline Embolism & 2 & I & I & I & I \\
\hline Compression of organs by blood & - & I & I & I & 2 \\
\hline Asphyxia & 14 & 2 & I & I & 20 \\
\hline Electric trauma & I & I & I & I & 4 \\
\hline Total cooling & - & 2 & I & 2 & 2 \\
\hline Thermal burns & - & I & I & 3 & 10 \\
\hline Poisoning & I & I & 5 & 7 & 23 \\
\hline Sudden death (diseases of the cardiovascular system) & 3 & 2 & 6 & 6 & 17 \\
\hline Total & 53 & 30 & 32 & 34 & 206 \\
\hline
\end{tabular}

\section{Results and discussion}

Serial studying of the expert materials and application of adequate methods of research with subsequent analysis of the obtained results allowed us to determine the 34 non-specific morphological features (criteria) with a high frequency of occurrence. In the first group, consisting of 53 cases of violent and non-violent death, with agonal period of 15-30 minutes twelve (12) morphological features were detected. In the second group, consisting of 30 cases of violent and non-violent death, six (6) morphological features revealed were revealed. In the third group, consisting of 32 cases of violent and non-violent death six (6) morphological features were revealed. In the fourth group, consisting of 34 cases of violent and non-violent death, five (5) morphological features were revealed. In the fifth group, consisting of 57 cases of violent and non-violent death, five 5 morphological features were revealed. At the final stage of the study these signs were used in the morphological-mathematical modeling of the process of dying, based on which it was possible to develop a scientifically a clear methodology for determining the duration and the rate of dying according to the morphological criteria. It should be emphasized, that during the study we have found that the subjective evaluation of the elements at the given positions depended on the skill of the expert and his experience of different expertises. It is not the same as having a negative impact on evidentiary value of conclusions or judgments. In order to establish the five options of death rate, we developed five morphological complexes in form of tables with description of morphological features and their diagnostic significance and estimated a limit of their total importance (Tables 2-6). The approbation of the proposed method on gross expert material in the end, improved scientific methodology of setting the death rate according to the morphological characteristics (criteria) for forensic practice, and enabled to set its own diagnostic limit and its total significance for each of the morphological complex. The limit of the total significance was 1,$21 ; 0,82 ; 0,66 ; 0,39 ; 2,1$ for the first, for the second, for the third for fourth and for the fifth complex, respectively. Thus, these tables represent a reference material, which is the basis for the evaluation of the total diagnostic significance of the revealed features to establish the duration of dying and the death rate in forensic practice.

In our work, we managed to establish morphological markers of death rate. These can be accessed from several positions. First of all, they have undoubted practical importance, as they allow to answer the questions of the investigating authorities, such as the questions about the origin of trauma, the ability of the mortally wounded to the active purposeful actions, etc. more accurately and, which is more important, reasonably. We hope that the facts mentioned above illustrate this position sufficiently. This explains the forensic value of this work as the crucial problem of this specific field of knowledge, which is forensic medicine. Moreover, the General pathological significance of the obtained results shows the morphological equivalent of thanatogenesis in respect to time. While its clinical parallels have already been described the morphological side has been studied insufficiently. This disadvantage was eliminated. The biological value of this work lies in the possibility to analyze patterns of destruction such a complex homeostatic system like the human body in the timeline. In particular we have found the evidence of a brilliant synthesis of academician Sarkisov D. S. on gradual time of the destruction of the functional systems on the sublevels of the organism in the process of thanatogenesis. Finally, our work also has a philosophical significance in terms of demonstrating the patterns of fracture of hierarchically organized functional systems. The concept of such systems were used in medical since the time of academician Anokhin P. K., but their destruction did not cause the attention of pathologists and forensic medicals. In particular, it demonstrates that the earliest changes occur in the most ancient systems of hemocirculation, however, their decay is observed last, and the substrate of higher nervous activity is destroyed irreversibly first. 
Table 2 The table of morphological signs (morphological complex I) to determine the lightning-fast rate of death

\begin{tabular}{|c|c|c|}
\hline $\begin{array}{l}\text { The index of } \\
\text { the sign }\end{array}$ & The description of the sign & $\begin{array}{l}\text { The index of } \\
\text { significance }\end{array}$ \\
\hline $\mathrm{X} 1$ & The absence or mild lung and brain edema & 0,29 \\
\hline $\mathrm{X} 2$ & $\begin{array}{l}\text { Fresh areactive haemorrhages into the parenchyma of } \\
\text { lungs and brain }\end{array}$ & 0,16 \\
\hline X3 & $\begin{array}{l}\text { Intumescense of neurons of midbrain reticular formation } \\
\text { with focal areactive cariolysis without expressed glial } \\
\text { reaction }\end{array}$ & 0,16 \\
\hline $\mathrm{X} 4$ & $\begin{array}{l}\text { Capillary plethora of internal organs, particularly lungs } \\
\text { and kidney cortexes }\end{array}$ & 0,19 \\
\hline X5 & $\begin{array}{l}\text { Acute changes of the myocardium on the type of diffuse } \\
\text { fragmentation and/or wave shaped cardiomiocytes and } \\
\text { other signs of cardiac thanatogenesis }\end{array}$ & 0,18 \\
\hline X6 & Absence so called shock realignment of haemodynamics & 0,24 \\
\hline X7 & High contents of lipids in the cortex of adrenal glands & 0,18 \\
\hline X8 & $\begin{array}{l}\text { Presence of the primary urine in the capsules of renal } \\
\text { glomerulus }\end{array}$ & 0,2 \\
\hline X9 & $\begin{array}{l}\text { Rapid development of autholisis in spleen and others } \\
\text { organs }\end{array}$ & 0,26 \\
\hline $\mathrm{X} 10$ & $\begin{array}{l}\text { Specialized vascular structures in lungs and brain in the } \\
\text { manner of so called enclosing arteries in case of rapid } \\
\text { dying show the picture of the spasm }\end{array}$ & 0,19 \\
\hline $\mathrm{X} 11$ & $\begin{array}{l}\text { IGH discovery (brown colouration) of small expression of } \\
\text { fibrinogen in the lung tissue }\end{array}$ & 0,18 \\
\hline $\mathrm{X} 12$ & $\begin{array}{l}\text { The absence of disseminated intravascular coagulation } \\
\text { (full absence microtrombus or their presence only in one } \\
\text { organ) and acute respiratory distress syndrome }\end{array}$ & 0,19 \\
\hline
\end{tabular}

Table 3 The table of morphological signs (morphological complex II) to determine the fast rate of death

\begin{tabular}{llr}
\hline $\begin{array}{l}\text { The index of the } \\
\text { sign }\end{array}$ & The description of the sign & The index of significance \\
\hline X1 & Brain edema & 0,28 \\
& $\begin{array}{l}\text { Ischemic changes of pyramidal neurons appear in the cerebral cortex, the } \\
\text { natural phenomenon of satellitosis in brain stem and focal neuronophagia of } \\
\text { cellular elements with signs of carolysis are observed }\end{array}$ & 0,26 \\
X2 & There are signs of centralization of circulation in kidneys & 0,27 \\
X3 & $\begin{array}{l}\text { Signs of the admixture to intraalveolar transudate of fibrinogen is observed in } \\
\text { the lungs, which likely reflects the initial signs of acute respiratory distress- }\end{array}$ & 0,28 \\
Syndrome of adults, naturally evolving in response to damage & $\begin{array}{l}\text { There are certainly areas of delipidization in the mesh area in adrenal glands } \\
\text { at this period } \\
\text { Autolysis of spleen and other organs is less exprsssed, and the rate of its } \\
\text { development is slow }\end{array}$ & 0,28 \\
X6 & & 0,27 \\
\hline
\end{tabular}

Table 4 The table of morphological signs (morphological complex III) to determine the average rate of death

\begin{tabular}{|c|c|c|}
\hline $\begin{array}{l}\text { The index } \\
\text { of the sign }\end{array}$ & The description of the sign & $\begin{array}{l}\text { The index of } \\
\text { significance }\end{array}$ \\
\hline $\mathrm{X} 1$ & Expressed brain edema & 0,24 \\
\hline $\mathrm{X} 2$ & $\begin{array}{l}\text { The ischemic changes of the pyramidal neurons in the cerebral cortex become extensive, individual } \\
\text { piknomoric neurons in the brain stem, satellitoses and focal neuronophagia of cellular elements with signs } \\
\text { of carolysis are observed }\end{array}$ & 0,23 \\
\hline $\mathrm{X} 3$ & Signs of centralization of circulation appear in kidneys & 0,13 \\
\hline $\mathrm{X} 4$ & $\begin{array}{l}\text { Signs of admixture of fibrin to intraalveolar transudate in the lungs are observed, which probably reflects the } \\
\text { occurrence of signs of respiratory distress-syndrome of adults, naturally evolving in response to the damage } \\
\text { ( } 8 \text { hours later intralveolar and glomerula intracapillary leukostasis first appears in the lungs, then diapedes of } \\
\text { leukocytes in the alveoli appears, even if the bronchi are intact) }\end{array}$ & 0,23 \\
\hline $\mathrm{X} 5$ & $\begin{array}{l}\text { There are certainly areas of delipidization in the mesh area and inner third of the beam in adrenal glands at } \\
\text { this period }\end{array}$ & 0,24 \\
\hline
\end{tabular}


Table Continued

\begin{tabular}{lll}
\hline $\begin{array}{l}\text { The index } \\
\text { of the sign }\end{array}$ & The description of the sign & $\begin{array}{l}\text { The index of } \\
\text { significance }\end{array}$ \\
\hline X6 & Signs of ARDS & 0,25 \\
\hline
\end{tabular}

Table 5 The table of morphological signs (morphological complex IV) to determine the slow rate of death

\begin{tabular}{ll}
\hline $\begin{array}{l}\text { The index of the } \\
\text { sign }\end{array}$ & The description of the sign \\
\hline X1 & $\begin{array}{l}\text { There is pronounced satellites and neuronophagia in the brain stem } \\
\text { In the lungs there is ARDS distinguishable in the application of routine stains, which is confirmed by IHC } \\
\text { study }\end{array}$ \\
X2 & $\begin{array}{l}\text { Dystrophic and necrotic changes of the initial tubular apparatus appear in the kidneys on the background } \\
\text { of centralization of blood flow }\end{array}$ \\
X3 & $\begin{array}{l}\text { Progressive symptoms of DIC } \\
\text { X4 }\end{array}$ \\
X5 & Progressive delipidization of fascicular zone in adrenal glands \\
\hline
\end{tabular}

Table 6 The table of morphological signs (morphological complex V) to determine the long tempo of death

\begin{tabular}{ll}
$\begin{array}{l}\text { The index } \\
\text { of the sign }\end{array}$ & The description of the sign \\
\hline X1 & $\begin{array}{l}\text { There were intraalveolar or panbronchiolitis focal accumulations of leukocytes with a mixture of fibrin in the } \\
\text { lungs in addition to the above-noted admixture of fibrin to the alveolar transudate; that meant purulent-fibrinous } \\
\text { pneumonia developed, the fibrin loses its mesh structure turned dense, eosinophilic, and sometimes met formed } \\
\text { hyaline membranes }\end{array}$ \\
significance
\end{tabular}

\section{Conclusion}

The results obtained within the study, in the study of morphological changes of major homeostatic systems of the human body in various categories and types of death shows that the death rate with agonal period of up to 12 hours can be diagnosed in four time periods. Morphological and statistical analysis allowed to reveal the most informative available morphological characters, including the cases with the use of immunohistochemistry in individuals with a known process of dying, allowed to confirm the previously established and highlight the new (34) non-specific morphological features (criteria) with a high frequency of occurrence. With the help of morphological and mathematical modeling of pathological processes of dying, abstracting from the underlying cause of death on a relatively intact background of observation, managed to develop a scientifically sound methodology for determining the rate of five dying according to the morphological characteristics (criteria), organized in complexes: i. Lightning-fast pace at which the agonal period should not exceed 15-30 minutes;

ii. The fast pace in which the agonal period is the time interval more than 30 minutes up to 2 hours;

iii. Average pace, when agonal period is the time interval over 2 hours and up to 6 hours;

iv. The slow pace at which the agonal period is the time interval over 6 hours and up to 12 hours;

v. Long tempo at which agonal period was more than 12 hours.

\section{Acknowledgements}

None.

\section{Conflict of interest}

Author declares that there is no conflict of interest. 